\title{
O TEMPO DA VIDA DO ESPÍRITO NA FILOSOFIA DE GASTON BACHELARD
}

\author{
Le Temps de la vie de l'espirit das la philosophie de Gaston Bachelard
}

Fernando da Silva Machado $^{1}$

\begin{abstract}
RESUMO: Nosso objetivo é mostrar como Bachelard edifica a noção de vida em sua filosofia ao esboçar uma reflexão sobre o problema filosófico do tempo junto às noções de instante e duração. O livro $A$ intuição do instante (1932), obra dedicada a esta reflexão metafísica sobre o tempo confluindo, quatro anos mais tarde, para $A$ dialética da duração (1936), obra que, por sua vez, define o conceito de duração a partir das várias temporalidades superpostas constitutivas da própria existência, são as referências privilegiadas deste estudo. Ressaltaremos a importância da filosofia de Henri Bergson nesta discussão ao estabelecermos um contraponto entre suas teses sobre a vida e a duração às mesmas teses conceituais bachelardianas, sobretudo a partir da oposição entre as seguintes noções: vida vivida (circunscrita ao tempo comum/tempo transitivo em Bergson) e vida pensada (circunscrita ao tempo do espírito/tempo imanente em Bachelard). Partimos da hipótese a ser debatida de que é porque o espírito pode chocar-se com a vida vulgar, escorregadia e homogênea que a vida superior, ou seja, do próprio espírito, deve ser entendida nesta filosofia bachelardiana como sendo uma construção racional ancorada em uma dialética pluralista de saberes sobre o tempo.
\end{abstract}

Palavras-chave: Bachelard. Bergson. Tempo, Instante. Duração. Vida.

RÉSUMÉ: Notre objectif est de montrer comment Bachelard construit la notion de la vie dans sa philosophie d'esquisser une réflexion sur le problème philosophique de temps ensemble les notions de temps et de la durée. Le livre L'intuition du instant (1932), un ouvrage consacré à cette réflexion métaphysique sur le temps convergeant, quatre ans plus tard, à la dialectique de la vie (1936), une œuvre qui, à son tour, définit la notion de temps de la Les différentes temporalités superposées constituant sa propre existence sont les références privilégiées de cette étude. Nous mettrons en évidence l'importance de la philosophie d'Henri Bergson cette discussion pour établir un contrepoint entre ses idées sur la vie et la durée pour les mêmes bachelardianas thèses théoriques, en particulier de l'opposition entre les notions suivantes: la vie vécue (limitée au temps commun / temps transitive Bergson) et la pensée de la vie (circonscrite à l'époque de l'esprit / temps immanent à Bachelard). Notre hypothèse débattue qu'il est parce que l'esprit peut tomber sur la vie vulgaire, glissante et homogène que la vie supérieure, qui est, l'esprit lui-même doit être

\footnotetext{
${ }^{1}$ Mestre em Filosofia pela Universidade Federal de Goiás (FAFIL-UFG).

Cadernos Cajuína, V. 3, N. 1, 2018, p. 24 - 34.
}

ISSN: 2448-0916 
compris dans cette philosophie bachelardien comme une construction rationnelle ancrée dans une dialectique pluraliste de la connaissance du temps.

Mots-clés: Bachelard. Bergson. Temps, instantané. Durée Vie

\section{INTRODUÇÃO}

Temos como referências privilegiadas nesta apresentação duas das obras bachelardianas da década de 30 que versam sobre o tempo, são elas: $A$ intuição do instante e A dialética da duração. A Primeira ideia que fixamos e que gostaríamos de estabelecer como pauta de discussão inicial levanta a questão da relação quase que evidente entre a noção de ritmo e instante nesta filosofia, talvez partindo ou usando como ponto de apoio a crítica à metáfora da vida bergsoniana apresentada por Bachelard no sétimo capítulo de $A$ dialética da duração, de título Metáforas musicais, mais detidamente.

Bachelard defendeu que a melodia musical não seria uma boa representação do fluxo da duração vital devido ao continuísmo implícito em sua constituição, defendida acentuadamente em Matéria e memória, de Bergson. Antes, Bachelard acreditava que o ritmo marcava o impulso que salta hiatos por meio de atos que reforçam nossas decisões vitais circunscritas ao instante atômico suspenso entre dois nada (partícula temporal). Na realidade fenomênica da música o ritmo não virtual é um ponto temporal com frequência surda, sem dimensão, mas que ocupa o eixo-espaço-tempo consciência com um impacto ondulatório facilmente captado pelo corpo e inteligência, contudo, sua realidade é apenas um flash, como gostava de dizer Michel Maffesoli em sua obra $O$ instante eterno: o retorno do trágico nas sociedades pós-modernas, ${ }^{2}$ pois seu fim determina sempre o limite de uma impulsão ou frequência, assim como a escuta do silêncio nadificador do intervalo que pode ou não ser suplantado por outro instante bem ondulado. Nesse domínio metafórico da realidade sonora o ritmo não continua nada, ele acorre por repetição e por diferença, e no mais das vezes permite com que tal melodia seja ampliada e se enforme de acordo com a constituição da onda sonora dada ao ouvido sensível. Contudo,

\footnotetext{
${ }^{2}$ Ver: MAFFESOLI, M. O instante eterno: o retorno do trágico nas sociedades pós-modernas. São Paulo: Zouk, 2003.
} 
apesar de parecer bem circunscrito o desenvolvimento de nossa discussão por esta via de análise, ou seja, a musical, o que propomos de fato versa sobre o tempo e a sua conexão com o conceito de vida nesta filosofia e ainda precisa de esclarecimentos mais elementares, como por exemplo, a importância da noção de descontinuidade do espírito junto à realidade básica so tempo, a do instante.

Ademais, é preciso mais a frente mirar no problema do substancialismo vital e o imediatismo psicológico bergsoniano (intuição) na esteira de uma oposição bem delineada pela filosofia bachelardiana do tempo, já que nos parece ser uma discussão que expande na medida em que impõe um "não" ${ }^{3}$ generalizador - à maneira da epistemologia negativa bachelardiana presente em $A$ filosofia do não (1940) e em O novo espírito científico (1940) - o escopo de análise do conceito de vida por meio de um paralelismo natural a ser evocado entre as duas filosofias em questão, ou seja, a de Bachelard e a de Bergson, dadas pela oposição marcante entre o conceito de continuidade e descontinuidade em um primeiro momento.

Logo que pensamos nestes termos (continuidade $x$ descontinuidade) percebemos que esta discussão revela um fundo mais profundo ainda, a constância de uma reflexão conduzida pelos dois autores em que a superposição comparativa entre suas teses acarretaria em um conflito inegável, envolvendo uma determinação ímpar não apenas da noção de duração, mas também do conceito de vida em cada filosofia. Pressupomos que esta reflexão apresentada em seguida sobre a vida interessa enormemente aos leitores dos dois pensadores e, talvez, seja esta determinação no pensamento bachelardiano do instante como única realidade puntiforme do tempo que dinamize sua reflexão filosófica como um todo, tanto pela via do pensamento objetivo, quanto da imaginação poética, assim como, de maneira semelhante, qualquer tese de cunho mobilista ou continuísta, como a bergsoniana da duração, por exemplo. Basta nos lembrarmos de que o lugar desta filosofia do tempo que suscita uma reflexão sobre a vida é também o locus em que emerge uma propedêutica a qualquer filosofia do repouso, da quietude do ser, de onde poderíamos alavancar uma metafísica ou mesmo ética em Bachelard, seja através dos valores vitais associados aos valores da razão (pensamento) ou mesmo aos valores poéticos. Diante da troca perpétua de valores entre o conhecimento criador

\footnotetext{
${ }^{3}$ Como diz Bachelard (1978, p.160), em "O novo espírito científico", "As paralelas existem depois, não antes do postulado de Euclides. A forma extensa do objeto microfísico existe depois, não antes, do método de detecção geométrica", a força da vida deve aparecer depois, e, portanto se estabelecer, a posteriori do tempo do espírito.
} 
da ciência e da arte - ou mesmo a substituição de valores em seu próprio registro ousamos defender que a dinamicidade do modo como o homem se reconstrói e se recria diante dos valores que o constitui, tal ato está intrinsicamente ligado à maneira como seu espírito se comporta diante das coisas e do mundo, vemos este movimento em torno da questão da existência na filosofia bachelardiana a partir do problema da vida bem remarcado em suas obras temporais via "um choque do espírito com a vida", cujo uma reflexão metafísica é indispensável (BACHELARD, 1994, p.16).

\section{PARA UMA FILOSOFIA TEMPORAL E VITAL NÃO-BERGSONIANA}

Bachelard remarcou em seus trabalhos epistemológicos que os objetos da realidade passaram a ser para o novo espírito científico uma teia de perspectivas de ideias. As ideias são as ferramentas de trabalho de uma micrometrologia francamente descontínua da nova ciência quântica e microfísica. Desta epistemologia ante-sensualista, ante-realista de primeira aproximação e antesubstancialista, defendida por Bachelard, decorre um combate contra o imediatismo e a fixidez não só da ciência e de uma noção de vida acabada e instável, marca de uma perspectiva simplista presente na tradição metafísica de pensamento. Tudo o que podemos conhecer, em torno destas noções, parece constituir um ponto decisivo nesta filosofia que estabelece uma inciativa metafísica de pensamento esboçada nestas obras sobre o tempo bachelardianas. Ressaltaremos ademais a recusa evidente ao bergsonismo continuísta temporal e vital à maneira de um nãocartesianismo, $^{4}$ ou seja, como medida de expansão e generalização do conhecimento via de um idealismo metafísico assumido por um Bachelard formalista, onde será necessário buscar um princípio de substância para além da contextura dos atributos, onde uma atividade noumenal evidenciaria um holismo necessário que busca apreender os fenômenos vitais em sua inteireza e complexidade fina.

\footnotetext{
${ }^{4}$ O que Bachelard (1978, p.161) condena no cartesianismo é seu caráter enquanto doutrina "das naturezas simples e absolutas", ele continua: "Com o novo espírito científico, é todo problema da intuição que se acha invertido". Todas as noções de base que validam um conceito mecanicista ou espiritualista de vida devem ceder a uma dualidade fundamental de noções complementares. $\mathrm{Na}$ realidade, não há fenômenos simples; o fenômeno é uma trama de relações. "Não há natureza simples, substância simples; a substância é uma contextura de atributos. Não há idéia simples, porque uma ideia simples, como viu muito bem Dupréel, deve ser inserida, para ser compreendida, num sistema complexo de pensamentos e de experiências" (BACHELARD, 1978, p. 164).
} 
A perspectiva principal defendida por Bachelard se deu a partir de uma reversão de uma categoria crucial que supostamente parecia sustentar qualquer reflexão sobre a duração, qual seja: a de instante, que se diferenciava completamente do entendimento de Bergson, vale remarcar, enquanto fragmentação do tempo concreto e como medida espacializada de uma inteligência demarcadora, descrevendo em seu lugar sua realidade como sendo única intuição original, objetiva e reveladora da dimensão verdadeiramente metafísica puntiforme de um projeto do tempo (construção temporal), amparada e corroborada pelas teses temporais tanto de Roupnel, quanto de Einstein. Ora, se mesmo a história das ciências na perspectiva epistemológica bachelardiana repercute a atitude do espírito diante do conhecimento e da realidade em meio às suas retomadas, rupturas e descontinuidades teóricas porque não pode o espírito "chocar-se contra a vida", ou seja, chocar-se com a vida comum e horizontal distribuída sob o fio homogêneo de uma duração supostamente contínua? Bachelard disse certa vez que "o pior inimigo da ciência é a própria ciência", são seus maus hábitos, seus métodos rígidos. De maneira similar podemos descrever que o pior inimigo da vida é a própria vida em sua contextura simples, onde o complexo surge do primário, ou melhor, em consequência dele: é sua taxa de ordinaridade que corrompe o espírito que parece a todo o momento querer recuperar sua turbulência e agressividade via um engajamento não apenas em prol da razão, mas também em prol da própria vida superior, ou seja, da vida harmoniosa e equilibrada de nosso eu pessoal criador, vislumbrado por esta filosofia do repouso bachelardiana que deseja antes de tudo rejuvenescer ao contemplar suas condições de aniquilamento e renascimento, e que de modo algum pode ser entendida aqui como uma filosofia da quietude, da inércia, já que a razão se impõe por si só e parece constituir uma vida estética através da inteligência, nestas condições ela já é vibração feliz.

De maneira resumida, para o Bachelard de $A$ intuição do instante, vida e hábito não devem ser reduzidos apenas à repetição e a uma diferenciação deveras comedida e pobre do germe vital, pois é preciso sempre depositar a confiança de nosso ser no instante lancinante de novidade. A este respeito afirma Bachelard (1994, p.28):

Basta, aliás, aprofundar a psicologia da hesitação para pôr nu o tecido dos sim e dos não. A vida se opõe à vida, o corpo devora a si mesmo e a alma rói. Não é a matéria que cria um obstáculo. As 
coisas são apenas a ocasião de nossas tentações. A tentação está em nós, como uma contradição moral e racional. Do modo mais evidente, também o medo está em nós antes do perigo. Como se compreenderia o perigo sem ele? E a mais insidiosa das inquietudes nasce da própria quietude. Quando nada me inquieta, diz Schopenhauer, é exatamente isso que parece inquietante. Basta materializar um pouco a afetividade para vê-la ondular.

Remarcamos a necessidade de uma retomada do valor da própria vida por intermédio de uma filosofia do repouso na esteira de um idealismo puro por parte de Bachelard presente em suas reflexões de cárter metafísico. Se no início de $A$ intuição do instante Bachelard diz que ante a qualquer reflexão metafísica é preciso pensar sobre o tempo, isso se dá porque qualquer ontologia que inclua a questão da vida, e não conhecemos nenhuma que não o faça, há que se submeter tudo que existe ao próprio tempo pensado, ao tempo do espírito. Ordenar o cogito $^{2}$ e cogito $^{3}$ a partir do eu formal ${ }^{5}$ é preciso, isso, chama-se, segundo Valéry, fundar uma álgebra dos atos que forjam ações "com atribuições múltiplas" e com dinâmicas bem definidas e ligadas entre cada um dos pulsos decisórios sobressaltados pela razão (BACHELARD, 1994, p.68). Este eu que dura, dura no e pelo espírito que é um tanto quanto imprudente e ansioso com a novidade demorada, à maneira de Schopenhauer, contudo, não deve ser entendido aqui como aquele do espiritualismo ou de qualquer misticismo, ele é o espaço superior em que um pensamento racional substancializado em forma de ideia e determinação vem atuar, ordenando a vida ou uma atenção ampla e consciente à ela, junto de uma expectativa em torná-la cada vez mais vibrada, alcançando, quem sabe, o repouso do ser através do desejo por uma novidade assentada.

Um paradigma que nos parece natural evocarmos então é que ser é tempo em Bachelard, ou seja, para nos tornarmos algo que visamos devemos atuar no instante tendendo a um fim e o esperando com paixão, recorrente em si, como a razão científica e a imaginação poética o fazem diante do instante de seus objetos, daí o pensador dizer que o único hábito fundamental do ser é recomeçar a si mesmo,

\footnotetext{
${ }^{5}$ Sob o eixo da razão, ritmo superior, o cogito elevado à terceira potência não propaga os hábitos ordinários de nossas ações que duram em sincronia com o tempo do mundo, antes, o cogito ${ }^{3} \mathrm{o}$ projeta, saltando sobre os nadas que hierarquicamente o separam do eixo temporal do cogito ${ }^{1}$ (eu material) e do eixo temporal do cogito $^{2}$ (eu psicológico/eu psicanalítico - história social do sujeito). Dessa acrobacia do ser que salta hiatos, convém remarcar, mais uma vez, se faz presente a descontinuidade do espírito em relação à vida: "é com efeito a partir do expoente três que se acede ao idealismo puro. [...]. Os tempos idealizados têm então constâncias, sem contudo ter uma continuidade" (BACHELARD, 1994, p.101).
} 
determinação, diga-se de passagem, que lembra muito a doutrina do eterno retorno nietzschiana fortalecida pela tese do eterno recomeço de Roupnel, resgatada holisticamente em sua obra de 1932. Portanto, o hábito do recomeço eterno estabelece as condições de acontecimento de uma vontade de ultrapassamento da vida quotidiana e comum que emana do próprio espírito.

\subsection{O espírito metafísico presente no pensamento vitalista-temporal bachelardiano}

Passamos à discussão do acesso metafísico-vitalista do pensamento filosófico bachelardiano. O que nos interessa mais detidamente nesta pequena apresentação é aquela metafísica do espírito científico de caráter discursivo de outrora presente em sua epistemologia, pensamos que um vitalismo metafísico se assenhora desta aqui nesta filosofia. A importância novamente da filosofia de Henri Bergson nessa discussão é inegável, foi confrontando primeiramente suas teses continuístas da duração que conseguimos definir a o problema da vida, central de $A$ dialética da duração, a partir da oposição entre vida vivida e vida pensada. Nossa tese inicial é que o choque entre espírito e vida poderia vir a revelar as condições de ultrapassamento da vida vivida, encantadora, inconsciente e homogênea que Bachelard parece reconhecer não só no poder regulador do espírito racional, mas também na alma poética, como aquela de Lautréamont, cuja personalidade influência o filósofo a escrever uma obra inteira de título homônimo, em 1940, dedicada à poesia de Ducasse, por exemplo. Bastaria recordamos da noção de vida invivível presente na escrita do poeta franco-uruguaio para legitimar nossa interpretação visivelmente atestada em Os cantos de Maldoror, onde parece claro a excessiva imposição da razão à alma poética e vice-versa: é à ideia instantânea e clara que devemos este privilégio da vida pensada e primitiva.

Do mesmo modo que uma complexidade explícita que permeia a vida superior (formal-cogito" ${ }^{1)}$ vem nos mostrar que o simples e o imediato não estão depositados nas coisas como determinaram os realistas de primeira aproximação, com efeito, viver envolve um esforço de construção, dito de outra maneira, viver é criar, e neste palco Bachelard nos mostrou que a arte e a ciência são verdadeiros artífices do saber. A bifurcação de suas fases de pensamento (diurno e noturno) se dá antes por necessidade de complexificação do pensamento criador do que pela 
busca resultante de uma cultura completa de saberes reunidos diante de uma tradição que soube esquecer tal junção entre razão e imaginação. Em vista disso, pouco importa a erudição, antes, importa a capacidade de criar diante da fixidez do mundo das formas prontas e acabadas: o homem complexo não é um avaro intelectual ou um erudito de peruca, mas sim liberto diante da complexidade da vida quando este retorna às fontes do espírito e da alma que revelam possibilidades e nada mais.

Entre o mundo destruído, da dúvida recorrente, e o mundo construído, mundo transitivo, do espírito científico e da alma poética, respectivamente, Bachelard pretendeu introduzir o mundo da retificação. A complexidade da construção vem suprimir a simplicidade da graça: o tempo pensado está livre para alocar o espírito decidido e aéreo. Quando deparamo-nos com o problema da vida, em Bergson, paralelamente à reflexão filosófica bachelardiana do tempo, notamos que a oposição entre o construído e o dado imediatamente são inconciliáveis entre estas filosofias em vias conclusivas de reflexão. O problema do continuísmo bergsoniano envolve a simplicidade de pensamento e a intuição direta do mundo que, segundo Bachelard, gera uma prolixidade desvairada a respeito do fenômeno da duração e sua conexão com a definição de vida. Simplificar o pensamento no intuito de atingir uma metafísica vitalista - dita imediatista e direta - constitui o sacrifício do próprio espírito em sua complexidade, o que ele tem de melhor, a riqueza de suas nuances, justamente porque ele tem como pilar a razão holística que radica o ser no mundo.

\subsection{O tempo equilibrado do espírito}

A duração pode ser o maior exemplo de uma construção complexa do pensamento pelo espírito em forma de superposições de temporalidades dadas ritmicamente, supõe Bachelard. É a carga de novidade que suspende sua sucessão na medida em que também permite a ligação entre estas temporalidades fragmentadas do ser. Enquanto única realidade intuída e pontual do tempo o instante é capaz de alterar o fluxo da duração por meio de atos de decisão que inauguram uma vida nova no mesmo passo em que a encerra. As teses temporais bachelardianas conciliadas à sua tese vitalista percorrem alguns caminhos labirínticos de construção, entre o instante simples e a construção da duração 
complexa superpõem-se causalidades temporais diversas (fisiológica, psicológica, etc). Ele chega, consequentemente, em meio a esta trama temporal muito bem organizada por uma razão suficiente até a tese central de sua filosofia do tempo que inaugura uma metafísica reveladora do ser que dura por meio de um equilíbrio ritmanalítico via uma energética materialista, baseado na no psicologismo terapêutico de Pinheiro dos Santos. Esta tese serve ao pensamento temporal bachelardiano de apoio ao argumento que sustenta a ideia de um retorno à intimidade do ser por meio de uma filosofia do repouso que permanece em estado de vibração constante.

$\mathrm{O}$ abandono da vida vivida ocorre porque no eixo do eu superior o ser "espiritualiza na proporção em que toma consciência de sua atividade formal, de seu grau cogitante", ou seja, em que toma consciência de que a vida pode ser feita de atos sem futuro, do mesmo modo como o causualismo quântico não espera ligar o fenômeno a um efeito (BACHELARD, 1994, p.88). Trata-se, portanto, de uma escolha racionalmente tomada e orientada, aqui, o inconsciente psicanalítico, o lugar escuro e escondido do eu não se sobrepõe ao pensamento claro. $O$ tempo real é o tempo de ascensão do espírito a um idealismo puro e ordenador, todas as outras temporalidades, sendo elas da ordem da matéria ou da psyché estão circunscritas ao tempo do intelecto, nas palavras de Hegel, retiradas por Bachelard de um texto de Koyré (apud Bachelard, 1994(a), p.88), o pensamento "é enriquecimento, vida, vitória. É ele próprio espírito e conceito". Talvez, a disjunção entre a filosofia de Bachelard e a de Bergson fora estabelecida em vista do poder de alcance do valor da vida retomado pelo pensamento a partir da ideia de um engajamento não apenas no âmbito racionalista da ciência contemporânea, mas de nós com nosso próprio eu, para isso, é preciso acreditar que "o repouso está inscrito no âmago do ser" e que ele só é atingido em prol de uma organização dos instantes complexos que se acumulam diante da vida.

No pensamento de Bachelard, resumiríamos, o bem viver, ou, para ser mais otimista, viver feliz, é um ato de inteligência proveniente de um esforço em assumir a vida e o valor de se viver diante de sua complexidade, isto parece constituir uma estética da inteligência. Portanto, atingir uma vida repousante comporta fugir dos ritmos ocasionais fundados sobre um tempo uniforme e regular, a duração é construída por ritmos pensados mais que vividos. 


\section{CONCLUSÃO}

É necessário também não perdemos de vista essa tendência contrária que permeia a ontologia bachelardiana ao ligarmos ao ritmo pensado o ritmo do devaneio poético. Concluímos oferecendo uma sugestão que deriva do que é afirmado em $A$ dialética da duração, aceita por Bachelard por sinal, para o tedium vitae, superpondo o tempo do espírito (energia de existência) ao tempo da vida através do ato poético. Mesmo Pinheiro dos Santos soube reconhecer nas obras de Valéry, por exemplo, "a arte suprema de perturbar a calma e de acalmar a perturbação, de ir do coração ao espírito para retornar logo do espírito ao coração" (BACHELARD, 1994(a), p.133). Para encerrar, se pudéssemos inspirar aqueles que assim como nós enxergam na poética bachelardiana a via extensa de uma ritmanálise vibratória que não aquela terapêutica de dos Santos que visava equilibrar o ritmo vital do espírito, mas como coriscar de um ascencionalismo vital latente nesta filosofia em que o eu pessoal repousa na duração pulverizada e que conquista este direito ao nada-ser e ser-agora, à felicidade, transcrevemos um verso singelo de Fernando Pessoa que cremos poder expressar o alcance deste pensamento ontológico e temporal que está aqui em jogo para nós, revelado pela dinâmica lírica de um poema dedicado a este homem quântico, superposto, complexo, de múltiplas facetas, mas não por isso incoerente, e que dura conforme progride, mas só avança quando re-começa:

"Minha alma é uma orquestra oculta

Só me conheço como sinfonia". ${ }^{6}$

\section{REFERÊNCIAS}

BACHELARD, G. A dialética da duração. Tradução Marcelo Coelho. 2.ed. São Paulo: Ática, 1994.

A formação do espírito científico. Tradução Estela dos Santos Abreu. 5.ed. Rio de Janeiro: Contraponto, 2005.

${ }^{6}$ CUNHA. R. S. O essencial sobre a ritmanálise. Lisboa: INCM, 2012. 
. A intuição do instante. Tradução Antonio de P. Danesi. 2.ed. Campinas: Verus, 2010.

. O novo espírito científico - col. Os Pensadores. Tradução Joaquim José Moura Ramos. 1.ed. São Paulo: Abril Cultural, 1978, p.93-179. 